\title{
Aproximações com a hermenêutica: um referencial para o trabalho docente no campo da Educação Física...
}

\author{
Ricardo Rezer* \\ Paulo Evaldo Fensterseifer** \\ Juarez Vieira do Nascimento***
}

\begin{abstract}
Resumo: O objetivo central desse artigo é refletir acerca das aproximações entre Educação Física (EF) e hermenêutica, como possibilidade de uma orientação para o trabalho docente nesse campo. Para tal, inicialmente, apresentamos os caminhos teórico-metodológicos. Após, discutimos acerca da presença de artigos que abordam ou se aproximam de uma discussão fundamentada pela hermenêutica, no campo da EF. Finalmente, apresentamos argumentos acerca das possibilidades de uma orientação hermenêutica para o trabalho docente no campo da EF brasileira.
\end{abstract}

Palavras-chave: Educação Física. Filosofia. Docentes.

\section{INTRODUÇÃO}

Qual o significado que a Hermenêutica tem hoje em dia? Eu espero que ela signifique um caminho para o pensar. Deve-se pensar por si mesmo. Não se aprende nada que não tenha sido pensado por si mesmo. Nisso ajuda. Para isso serve a hermenêutica, uma vez que ela deixa muita coisa em aberto. É essa a natureza da hermenêutica, pois ela não diz

\footnotetext{
${ }^{1}$ Este artigo trata-se de um recorte do Capítulo III da Tese de Doutorado O trabalho docente na formação inicial em Educação Física: reflexões epistemológicas... Cabe destacar que a tese aborda diferentes aspectos do trabalho docente na formação inicial em EF e a hermenêutica se constituiu como um orientador importante, presente ao longo do desenvolvimento da investigação, desenvolvida entre 2007 e 2010.

*Universidade Comunitária da Região de Chapecó (Unochapeco). Chapecó, SC, Brasil. E-mail: rrezer@hotmail.com

${ }^{*}$ Universidade Regional do Noroeste do Estado do Rio Grande do Sul. Unijui. ljuí, RS, Brasil Email: fenster@unijui.edu.br

${ }^{* * *}$ Universidade Federal de Santa Catarina (UFSC). Florianópolis, SC, Brasil. E-mail: juarezvn@cds.ufsc.br
} 
exatamente o que se quer dizer. Ela é assim como toda pergunta: cada pergunta é um fenômeno hermenêutico. Pois a resposta não é definitiva. (GADAMER, 2001, p. 14).

Lendo a resposta de Gadamer (2001) na epígrafe apresentada, nos sentimos provocados a pensar os desdobramentos desta compreensão para o campo educacional e em particular, para a Educação Física (EF). É justamente esta a pretensão deste artigo, abordar possíveis aproximações entre EF e hermenêutica na realidade brasileira, tomando como referência o diálogo com textos publicados em periódicos especializados nacionais, vinculados ao campo da EF, que abordem esta discussão. Desta forma, o objetivo central é refletir acerca das aproximações entre EF e hermenêutica, apresentando possibilidades para uma orientação hermenêutica do trabalho docente nesse campo.

Conforme Lawn (2007), a palavra hermenêutica é derivada do grego, "interpretar", e tem duas origens. Uma do deus grego Hermes em seu papel de mensageiro dos céus, enquanto que outra se refere ao conhecimento oculto e secreto digno de interpretação. Palmer (2006) contribui com a compreensão acerca das origens do termo, quando afirma que ele é usualmente traduzido por "interpretar" e no substantivo (hermeneia), que significa "interpretação". Assim, uma das raízes do termo "hermenêutica" pode ser encontrada no termo grego hermeneuein, usualmente traduzido por interpretar (ou hermeneia: interpretação). Para Ruedell (2005), essas duas palavras remetem a mitologia grega, mais precisamente a Hermes, o deus mensageiro ${ }^{2}$.

Ao compreender a hermenêutica como um caminho para o pensar, como proposto na epígrafe inicial, articular possibilidades de aproximação entre hermenêutica e o trabalho docente na EF não se

\footnotetext{
${ }^{2} \mathrm{Hermes}$ associa-se a transmutação, aproximando o que era distante e obscuro a algo possível de ser conhecido. Palmer (2006) afirma que tal origem entende o processo hermenêutico como uma possibilidade de "transformar tudo aquilo que ultrapassa a compreensão humana em algo que essa inteligência possa compreender". Hermes traz a mensagem do destino. Hermeneuein é esse descobrir de qualquer coisa que traz uma mensagem, na medida em que o que se mostra pode tornar-se mensagem, sugerindo o processo de tornar compreensível. (PLMER, 2006, p. 24).
} 
trata de pouca coisa. Principalmente pela proximidade do trabalho docente com a hermenêutica, no sentido de que o trabalho docente se propõe a possibilitar que algo antes não conhecido, estranho, passe a se tornar familiar, conhecido, tanto no que se refere aos discentes como aos docentes.

Partindo dessas breves considerações iniciais, a seguir, apresentamos os caminhos teórico-metodológicos deste esforço investigativo. Em um segundo momento, discutimos acerca da presença de artigos que abordem ou se aproximem de uma discussão fundamentada pela hermenêutica, no campo da EF. Finalmente, apresentamos argumentos acerca das possibilidades para uma orientação hermenêutica ao trabalho docente na EF brasileira.

\section{Caminhos teórico-metodológicos}

Este estudo caracterizou-se como sendo de natureza descritiva bibliográfica, pautado por uma orientação hermenêutica. Em seu desenvolvimento, partindo de palavras-chaves, desenvolvemos uma busca que possibilitasse encontrar referenciais hermenêuticos no campo da EF brasileira. Para tal, foram estabelecidas oito fontes de consultas: sete periódicos e uma biblioteca digital, todos vinculados ao campo da EF, no intuito de identificar a presença de artigos que abordem ou se aproximem de uma discussão fundamentada pela hermenêutica. Tais bases foram selecionadas devido à acessibilidade dos pesquisadores, bem como, por constituírem confiável fonte de consulta.

Nesse processo, baseados em Palmer (2006), compreendemos hermenêutica por "interpretar" e no substantivo (hermeneia), por "interpretação". Partindo disso, conforme Heidegger (2009), a interpretação e também, a compreensão passam a representar modos fundantes da existência humana. Assim sendo, "interpretação" e "compreensão" adquirem um caráter de centralidade na discussão hermenêutica. 
Partindo destes argumentos, a busca foi realizada no campo "pesquisa" dos periódicos, utilizando os seguintes descritores (inglês/ português): "hermenêutica"; "interpretação" e "compreensão". O processo de busca se desenvolveu entre 9 e 30 de junho de 2010 nos endereços eletrônicos dos periódicos selecionados. Inicialmente, 243 estudos apresentaram no título ou nas palavras-chave, pelo menos, um dos descritores. Dessa forma, todos foram selecionados para uma próxima etapa: a leitura do resumo. Após este procedimento inicial, foram selecionadas as publicações que se valiam de referencial hermenêutico em seu desenvolvimento, expressando textualmente nos resumos esta pretensão. O resultado da busca está representado no quadro a seguir:

\begin{tabular}{|l|c|c|c|}
\hline Periódico/Descritor & $\begin{array}{c}\text { Artigos } \\
\text { Hermenêutica }\end{array}$ & $\begin{array}{c}\text { Artigos } \\
\text { Interpretação }\end{array}$ & $\begin{array}{c}\text { Artigos } \\
\text { Compreensão }\end{array}$ \\
\hline RBCE & 2 & 5 & 10 \\
\hline Movimento & 2 & 23 & 41 \\
\hline Motriz & 1 & 7 & 25 \\
\hline Motrivivência & 3 & 3 & 13 \\
\hline Pensar a Prática & 1 & 15 & 43 \\
\hline RBEFELD & 0 & 9 & 18 \\
\hline RBEFE & 1 & 2 & 8 \\
\hline Boletim EF & 0 & 2 & 9 \\
\hline Total & 10 & 66 & 167 \\
\hline
\end{tabular}

Quadro 1- A presença da hermenêutica em periódicos da EF brasileira.

Relacionados diretamente a hermenêutica, foram identificados 10 artigos, nominados no Quadro 1. Já com relação ao descritor "interpretação" foram identificados 66 artigos e com relação ao descritor "compreensão" foram identificados 167 artigos - estes dois últimos termos, totalizando 233 artigos não foram identificados no Quadro 1 devido ao extenso número. Cabe destacar que estes 223 artigos identificados a partir dos descritores "compreensão" e "interpretação" não se referiam diretamente a um referencial hermenêutico. Mesmo em pequeno número, os artigos proporcionaram elementos importantes para a discussão ora proposta. A seguir, serão apresentadas as principais considerações a respeito dos 'achados' desse processo. 


\section{A dISCUSSÃO HERMENÊUTICA PRESENTE EM ARTIGOS PUBLICADOS EM PERIÓDICOS DA EF BRASILEIRA.}

As discussões estabelecidas anteriormente suscitam a discussão proposta para este tópico. Ou seja, a EF vem se interessando por pressupostos da hermenêutica? Baseado em uma busca de evidências acerca dessa questão em periódicos da EF brasileira, chegamos as seguintes considerações, derivadas de um recorte que se propõe a apontar referências acerca da discussão proposta.

Os artigos identificados foram publicados no período compreendido entre 2003 e 2009 , totalizando 10 artigos, que foram estudados na íntegra. Inicialmente, baseado nestes números, é possível inferir que o interesse pela hermenêutica no campo da EF ainda é incipiente, o que pode ser derivado de algumas hipóteses: a) trata-se de uma teoria ainda pouco conhecida neste campo; b) por ser pouco conhecida ainda, não vem despertando interesse dos pesquisadores; c) pode ser considerada como basicamente uma filosofia que não proporciona contribuições a um campo do conhecimento que se caracteriza pela intervenção 'prática'; entre outras possibilidades ${ }^{3}$.

Após este processo de busca, entende-se que o interesse pela discussão fundamentada em pressupostos hermenêuticos parece ser, realmente, ainda incipiente no âmbito da EF brasileira. E mesmo em meio aos artigos identificados que abordam esta teoria, alguns ainda a tratam perspectivada pela noção de metodologia ou método de pesquisa, tomando-a como "suporte" no processo de "tratamento" e "análise de dados". Nesse caso, é possível inferir que ainda é recorrente a noção de hermenêutica como método ou metodologia

\footnotetext{
${ }^{3}$ Por outro lado, 233 artigos, mesmo sem referência direta à hermenêutica, com diferentes intenções, apresentavam em seu desenvolvimento os termos "interpretação" e "compreensão". Isso permite inferir sobre um relativo interesse de pesquisadores em interpretar e compreender elementos relacionados ao campo da EF. Isso representa um interesse que a discussão hermenêutica poderia alargar, apresentando subsídios que permitiriam considerar incrementos na produção acadêmica da EF que se preocupe com o esforço interpretativo de determinados fenômenos presentes em seu interior, objetivando ampliar a compreensão do próprio campo a seu respeito, em um movimento que permita um "olhar-para-sí", sem perder noção de contexto, esforço com o qual a hermenêutica pode contribuir.
} 
(PORPINO, 2004; CARDOSO, 2004; HIRAI E CARDOSO, 2006; HIRAI; CARDOSO, 2009), como "método de análise" (TAVARES; SOARES; BARTHOLO, 2007), ou ainda, como um método hermenêutico (SANCHEZ NETO; BETTI, 2008).

Pode ser interessante fundamentar a opção metodológica a partir de uma noção hermenêutica para a interpretação de "achados" de diferentes pesquisas. Porém, a idéia de tratá-la como se fosse uma metodologia, abre mão das maiores possibilidades da hermenêutica, ou seja, conforme expresso por Gadamer (2001), "um caminho para o pensar". Obstante, se entendermos "método" a partir dos gregos (caminho para), tratar a hermenêutica como método ou metodologia, não se trata de um equívoco, apenas, uma opção limitada.

Para Gadamer (2006), a hermenêutica não é apenas uma disciplina auxiliar que representa para muitas disciplinas uma ferramenta metodológica adicional. Uma orientação hermenêutica "ajuda a pensar" um conjunto de possibilidades. Por exemplo, mais que uma metodologia, orienta e amplia a possibilidade de pensar desde o tema, o problema da pesquisa, as opções teóricas, e inclusive, a metodologia do estudo e a forma de lidar com os "achados". Isso implica em afirmar que a hermenêutica, mais que uma metodologia, trata-se, como se refere Ruedell (2005a, p. 19), de um modo de pensar, no qual a questão hermenêutica se situa em um nível mais profundo, "[...] para além de toda discussão objetiva, onde sujeito e objeto são inseparáveis, onde há uma circularidade entre o todo e as partes e, enfim, há sempre um ponto de vista ou uma précompreensão"

Ou seja, uma orientação hermenêutica pode contribuir com avanços na forma de pensar as relações entre sujeito e objeto, permitindo inclusive, entender a precariedade de estabelecer a relação sujeito-objeto nos moldes da chamada "ciência normal"4. Daí a noção de jogo proposta por Gadamer (2007), no qual sujeito e

\footnotetext{
${ }^{4}$ Para Kuhn (2006, p. 29), a ciência normal é entendida como propostas investigativas firmemente baseadas em uma ou mais realizações científicas passadas. Tais realizações são reconhecidas durante algum tempo por alguma (s) comunidade (s) científica (s), proporcionando os fundamentos para sua prática posterior.
} 
objeto "trocam" constantemente de lugar, em que o sujeito é "jogado pelo jogo", conduz e é conduzido, ou ainda, neste caso, jogado pela própria pesquisa. Estendendo a noção de jogo a sala de aula, o professor passa a ser jogado pela aula, tanto quanto é sujeito do processo, por vezes, sem perceber. A experiência pedagógica assume então, o caráter de "acontecimento" 5 . Desta forma, isso nos envolve e propicia ao ser humano uma experiência hermenêutica aberta, pressupondo o desafio da interpretação como uma tarefa inesgotável (RUEDELL, 2005a, p. 19).

Se para Gadamer (2007) a "verdade" não se estabelece pelo método (que pode até mesmo ofuscá-la), mas sim pelo diálogo interminável, sempre renovado pelos argumentos apresentados, pressupor a hermenêutica como uma metodologia minimiza seu alcance, reduzindo sua complexidade a técnicas de investigação. No caso deste artigo, se não prescindimos do rigor do método, da mesma forma, não nos iludimos acerca de suas possibilidades e pretensões.

De outra forma, também é possível perceber ainda a noção de hermenêutica como uma possibilidade de chegar ao que o autor "quis dizer". Como exemplo, fundamentados em Schleiermacher, Hirai e Cardoso (2009, p. 103), entendem-na como "a arte da compreensão correta do discurso de um outro". Nesse caso, avançando na proposição de Schleiermacher, Gadamer (2007) propõe a noção de "fusão de horizontes" 6 , referido anteriormente, como uma representação para o encontro entre o horizonte do autor e o horizonte do intérprete, o que pressupõe uma tarefa hermenêutica.

\footnotetext{
${ }^{5} \mathrm{~A}$ experiência (Erfahrung no original alemão) "expressa uma vivência pela qual aprendemos" (Hermann, 2010, p. 15), distinguindo-se da experiência científica, que certifica o já sabido.

${ }^{6}$ Um horizonte, conforme Gadamer (2007), não é uma fronteira rígida, mas algo que se desloca conosco, conforme nosso avanço, e que convida a seguir adentrando, se movendo junto com nosso próprio avanço. Contribuindo com essa questão, Lawn (2007) lembra que se trata de um termo usado inicialmente por Nietzsche e Husserl, para se referir a determinado ponto de vista ou perspectiva do mundo. Gadamer o entende como o alcance da visão que inclui tudo que pode ser visto, a partir de uma determinada perspectiva de mundo (2007, p. 304). Nessa direção, para Gadamer, a "Fusão de horizontes" trata-se de uma expressão importante, que descreve a possibilidade do entendimento. Desta forma, cada sujeito perspectiva o mundo através de um horizonte e, na tentativa de estabelecer entendimento com outros, estes horizontes avançam ou recuam, modificando a forma como o sujeito se relaciona com o mundo e consigo mesmo.
} 
Tratando a hermenêutica por esta orientação, o esforço ora proposto, se apresenta como uma possibilidade de tencionar as possibilidades da hermenêutica vir a compor um cenário de aproximações com a EF, como um orientador do processo de condução de diferentes processos investigativos e do trabalho docente. Como exemplo de abordagens que se aproximam das argumentações aqui apresentadas, é possível referenciar alguns estudos aqui identificados, nomeadamente os estudos de Fiamoncini (2003), Sanchez Neto (2008), Alves (2009) e Fensterseifer (2009).

O estudo de Alves (2009) se propõe a observar o esforço de investigação das Ciências Humanas sob a perspectiva da hermenêutica filosófica de Gadamer. Esta aproximação, segundo o autor, permite indagar sobre possibilidades da EF ampliar seu âmbito de conhecimento ao levar em conta o corpo e o movimento como agentes potenciais de história, revelando uma afinidade ontológica entre campos distintos de conhecimento. Nesse caso, a hermenêutica tornaria esta comunicação compreensível na verificação de um interlocutor e é esta verificação - e as possibilidades ainda não desbravadas que ela anuncia - que poderia interessar à EF. Essa discussão corrobora, embora realizadas em tempos diferentes, com algumas investidas de Cardoso (2004), em que ele afirma que é com base na Filosofia Hermenêutica e na Dialética que poderemos tentar ampliar a compreensão da corporeidade, do "se-movimentar", e demais faculdades que pertencem aos seres humanos que, acrescentamos, interessam a EF.

Já Fiamoncini (2003) procura desenvolver uma fundamentação teórica para a dança na educação, com base em elementos da arte e da estética. Elege como pressuposto metodológico a realização de um aprofundamento teórico, e aqui entra o interesse na abordagem por ela proposta, baseada na hermenêutica. Na arte, segundo a autora, são identificados como primordiais a criatividade e a expressividade, e na estética, a sensibilidade, daí a relevância das contribuições da hermenêutica balizada por Gadamer (2001). A autora 
conclui que são esses elementos fundamentais, que formam o tripé básico para o trabalho com a dança tanto na educação formal quanto na educação informal.

Nessa mesma linha, trazendo a discussão para a EF escolar, Sanchez Neto e Betti (2008) procuram apresentar e analisar uma proposta para fundamentar a intervenção de professores de EF. Realizaram uma revisão crítica de propostas elaboradas na área, especialmente nas duas últimas décadas do Século XX, procurando interpretar relações entre diferentes tendências da EF brasileira ${ }^{7}$. Tal esforço pautou suas análises a partir do "método hermenêutico", baseando-se para tal investida em Paul Ricoeur. Mesmo que tratando a hermenêutica de forma muito próxima a uma metodologia, a orientação de Ricoeur contribui na perspectiva de pensar possibilidades para a EF constituir o que ele denomina de "solo ontológico" entre diferentes discursos que a constituem.

Mesmo que pensado por caminhos diferentes do artigo de Sanchez Neto e Betti, Fensterseifer (2009) contribui na discussão ora proposta, afirmando que, a partir da hermenêutica, podemos suspeitar de verdades que buscam validar-se de modo imperativo, como se algo "natural" ou "sobrenatural" lhes dotasse de crédito. "Logo, a tarefa epistemológica, orientada hermeneuticamente, não se faz apelando a referências exteriores (teológicas ou naturais), mas do interior de padrões finitos de verdade.". (SANCHEZ NETO; BETTI; FENSTERSEIFER, 2009, p. 248).

Essa referência pode permitir maior discernimento frente a diversidade da EF brasileira, ao invés de ter de escolher aquela tendência que mais "agrada" ao professor. Mais do que um ecletismo, pensar a hermenêutica como pressuposto orientador para a docência poderia ampliar a capacidade de lidar com o diferente, visto que,

\footnotetext{
${ }^{7}$ Os autores concluem, com base nesta revisão, que uma aproximação entre as tendências analisadas é condição necessária para uma melhor compreensão da EF Escolar, afirmando que os professores podem utilizar diversos elementos constitutivos para solucionar problemas cotidianos.
} 
inicialmente, ao invés de defender idéias, posições e argumentos, estudantes e professores poderiam ampliar possibilidades dialógicas, partindo do pressuposto que a construção da verdade se dá por produção de sentidos em contextos coletivos $^{8}$. Pois, como alerta Hermann (2010, p. 117)

Na prática educativa, quando se antecipa a pretensão do outro, por meio de conhecimentos científicos, se estabelece o risco da relação autoritária e violenta, pois o outro deve seguir determinações que não passam pelo reconhecimento. Tal forma de proceder é objetificadora e não consegue reconhecer a alteridade. Em parte isso ocorre quando a idéia de formação é atrelada exclusivamente a uma racionalidade científica.

Se ainda não é perceptível o envolvimento da EF contemporânea com tal tema, é preciso reconhecer inicialmente que a hermenêutica trata-se de mais que uma "ferramenta metodológica", mas um pressuposto orientador que se traduz em um amplo espectro de referenciais, que nos conduz a "ler" os problemas do mundo por diferentes perspectivas, que se fundem com outras e já se transforma a partir disso ou, por outro lado, se mantém, até que uma nova inspeção permita superá-la, ou não.

A tarefa nada fácil que fica é trazer objetivamente essa discussão para o campo da EF, tomando a hermenêutica como referencial orientador, tanto para a produção do conhecimento, que se constitui como pressuposto orientador para a intervenção, quanto para a intervenção, que se constitui como pressuposto orientador para a produção, em um movimento circular, tal como um círculo hermenêutico orientador para o campo da $\mathrm{EF}$, algo bem mais ampliado que uma metodologia de pesquisa.

\footnotetext{
${ }^{8} \mathrm{Ao}$ assumir a compreensão do professor como um intérprete, todo um horizonte se abre, e o exercício da docência passa realmente a ter como condição fundante a produção de sentidos, revisitando a tradição do mundo pelo hoje dos protagonistas que dela se aproximam, tanto na condição de professor como na condição de aluno.
} 


\section{UMA ORIENTAÇÃO HERMENÊUTICA PARA O TRABALHO DOCENTE NA EF...}

As práticas em sala de aula possuem em sua base de sustentação uma discussão hermenêutica (RUEDELL, 2007). Nesse sentido, na aula, na medida em que se "transmite"' e/ou se constrói conhecimento e se partilha responsabilidade, é possível identificar a presença da hermenêutica como um caminho que permite a construção de sentidos novos para conteúdos que já existem e que representam, em determinada medida, a tradição do mundo.

Ou seja, ensinar, esforço que exige compreensão, não se dá fora de um contexto, de uma cultura, enfim, de uma tradição. Considerar com seriedade o referencial hermenêutico significa que o esforço da docência pressupõe a apropriação de uma tradição, porém, sem diluir-se nela, assumindo uma postura de respeito e ao mesmo tempo de desconfiança. Nesse sentido, Fensterseifer (2009) afirma que nossa tradição crítica demanda que possamos dizer "sim" ou "não" a esta tradição, mesmo reconhecendo que este esforço crítico se esboce do interior da mesma tradição.

Essa compreensão passa pelo esforço hermenêutico do professor em traduzir, com autoridade ${ }^{9}$, determinados conhecimentos para contextos de aula onde diferentes sujeitos se encontram, possivelmente, abertos a possibilidades da experiência genuína.

Mesmo que por outros caminhos, mas não menos importantes, Tardif e Lessard (2005) também reconhecem que o exercício da docência é uma tarefa eminentemente hermenêutica. Se, conforme Heidegger (2009), a compreensão e a interpretação são modos fundantes da existência humana, as exigências do "ser-professor" consistem em interpretar e compreender determinados conhecimentos, promovendo "recortes epistemológicos", perspectivando novas leituras, estabelecendo caminhos teórico-

\footnotetext{
${ }^{9}$ No que se refere a autoridade, Gadamer (2007) entende que ter autoridade é conhecer com profundidade, "algo" que está dentro da tradição, sem diluir-se nem no "algo" nem na tradição.
} 
metodológicos para a docência, a partir de uma compreensão pedagógica da tarefa educacional ${ }^{10}$.

Conforme Berticelli (2004), busca de conhecimentos é sempre busca de sentidos. Assim, se apresenta uma complexa tarefa educacional: dotar a intervenção do professor e o conhecimento a ser tratado de sentido, processo que requer negociação e uma confluência de sentidos entre professor e aluno, em um processo dialético que somente acaba pelos prazos de uma disciplina. Uma experiência desta monta não se contenta com modelos aplicacionistas (no sentido restrito do termo) baseados na perspectiva de um sujeito que intervém sobre outro, como por exemplo, ensinado um programa de exercícios ou algum esporte. É preciso reconhecer que a intervenção pedagógica se dá com os outros e não sobre os outros. $\mathrm{O}$ encontro entre aluno e professor, seus diferentes mundos, pode permitir uma ampliação da janela pela qual ambos vêem seus próprios mundos, ampliando a própria compreensão construída pela tradição do campo da EF.

Lembrando Fensterseifer (2009), a consideração deste referencial nos possibilitaria redimensionar a questão do conhecimento, visto que implicaria em uma inflexão no entendimento da racionalidade hegemônica ocidental com suas devidas implicações para os diferentes campos do saber.

Ao propor a hermenêutica como uma referência para o trabalho docente na EF, é possível resgatar a responsabilidade docente com a construção do próprio campo. Nessa proposição, baseado principalmente em Berticelli (2004), Palmer (2006), Gadamer (2007) e Lawn (2007), entendemos a docência em EF como um jogo de pergunta e resposta. Nesse caso, ao invés da noção "sujeito-objeto", é possível considerar a noção dialética da pergunta e da resposta, fundamentada em Gadamer (2007), como referencial orientador.

\footnotetext{
${ }^{10}$ Conforme Palmer (2006), referindo-se aos professores de Literatura, temos que nos tornar peritos em tradução, transformando algo que é estranho, pouco familiar, distante e obscuro do horizonte dos alunos, em algo que tenha significado, próximo, e inteligível. Este encontro acontece no seio de uma tradição, o que permite um processo de revisitar os temas abordados a cada encontro, a cada aula, em um sempre diferente "de novo".
} 
Assim, o referencial essencial da interpretação é a pergunta, que sempre coloca o sujeito em um espaço aberto, uma vez que a resposta não está determinada. Compreender é compreender uma pergunta, em um momento que os interlocutores conseguem colocar-se num horizonte compartilhado, orientado pelo horizonte da própria pergunta. Eis, conforme Berticelli (2004), um círculo, o círculo hermenêutico, que pela dialética da pergunta e da resposta conduz ás profundezas da epistemologia ${ }^{11}$.

Como exemplo, é possível ilustrar a idéia de envolvimento através da experiência da arte. Para Gadamer (2002), uma condição para entender a arte não pode ser o distanciamento, comum em uma relação sujeito-objeto, muito recorrente na "ciência normal" (KUHN, 2006), mas sim, uma aproximação, uma participação, um envolvimento engajado. Pensar a docência, a partir da referência da obra de arte, como um movimento engajado que não pode prescindir de envolvimento, esforço que não combina com distanciamento, apresenta novas referências acerca das aproximações entre hermenêutica e a docência ${ }^{12}$.

Concordando com Berticelli (2004, p. 309), a mesma dinâmica da pergunta e da resposta é obedecida neste processo, na instauração de sentidos sem que se estabeleçam fronteiras delimitadas e/ou intransponíveis. O autor ainda afirma que "Não é, pois, sem dificuldades, que se pode seguir o caminho da hermenêutica como recurso epistêmico na instauração de sentido do processo educacional".

\footnotetext{
${ }^{11}$ Nesta relação entre professor, aluno e conhecimento, lembrando Milovic (2004, p. 124), algo sempre fica escondido, sobre o qual o questionamento epistemológico não consegue avançar, mas possivelmente a hermenêutica poderia revelar. Nesse caso, é possível pensar nos mistérios da docência como um desafio importante e inerente ao trabalho cotidiano, o que requer envolvimento.

${ }^{12}$ Da mesma forma, é importante considerar que o esforço aqui proposto parte da idéia, conforme Gadamer (2007), de que, assim como a obra de arte, o encontro entre diferentes horizontes, bem como, o processo de produção de sentidos na perspectiva de ensinar e de aprender nunca é alcançado plenamente. Marques (1993) se refere a este processo como algo que, por nossa condição humana, nunca pode ser aprendido de vez. Entre o que o professor fala e aquilo que o aluno escuta, há literalmente, um mundo de distância. Um dos objetivos do trabalho docente seria diminuir a distância entre estes mundos pela construção de sentidos em comum.
} 
Assim sendo, partindo destes argumentos, uma orientação hermenêutica para o trabalho docente pode conduzir "[...] a um campo de liberdade do fazer educativo que nos afasta de pressupostos dogmáticos e fundacionalistas por princípio. Esta é uma condição atrativa e motivadora ante as demandas de novas formas de entender o conhecimento em nosso tempo". (BERTICELLI, 2004, p. 297).

Assumindo esta postura, não há como "repetir matéria" na sala de aula. Mesmo considerando o ponto de partida 'original' da matéria ou conceitos "estáticos" nela presente, uma confluência de sentido necessita acontecer em diferentes momentos da aula, o que pode abrir e fechar caminhos, muitas vezes, com uma velocidade impressionante. Isso obriga ao professor uma condição de vigilância sobre aquilo que "aparece" na aula ${ }^{13}$.

A arte de interpretar e compreender o que "aparece", se levada a sério, permite um retorno ao próprio sujeito em um processo de inflexão que lhe permite um maior conhecimento de si, portanto, de maior maturidade para saber dos próprios limites e potenciais. Nesse caso, as relações deste sujeito com o mundo não serão nunca mais as mesmas, pela ampliação da compreensão e dos horizontes no qual nos movimentamos. Concordando com Ricoeur (2008), aqui neste entremeio, se apresenta a crítica, que permite perspectivar possibilidades de transformação abertas pela interpretação e pela compreensão.

Ou seja, a hermenêutica pode ser compreendida como um princípio transformador, postura essa de extrema relevância no trabalho docente na EF. Nesse caso, a pertinência do esforço hermenêutico aqui pretendido, pode permitir que essa discussão

\footnotetext{
${ }^{13}$ Por isso, é importante considerar o "instante-já" (expressão de Clarice Lispector, 1998), nesse caso, da docência, esforço que requer envolvimento, sensibilidade e conhecimento. Se cada coisa tem o instante que ela é, é possível afirmar que cada aula tem sua história, em um sempre "de novo", que nos coloca em uma condição de novidade e repetição a cada encontro. Esse esforço se aproxima daquilo que Heidegger se referiu como nosso modo de estar aí (Dasein). Em Ser e Tempo, Heidegger (2009) trabalha com a idéia de que o homem constrói o seu modo de ser, a sua existência, a sua história em seu Dasein, em seu estar aí. Essa condição se apresenta como nevrálgica no trabalho docente, visto que, se cada aula pode se constituir como uma experiência, assumindo uma postura heidegeriana, nunca entramos ou saímos da mesma forma neste processo.
} 
aconteça "por dentro" da EF. Assim, a riqueza do movimento hermenêutico aqui proposto se refere ao sentido da interpretação, que gera sempre novas e maiores janelas para o mundo, o que permite a construção de aberturas rumo a uma nova dimensão do que entendemos como real sem termos sobre ele uma posição definitiva.

A compreensão gadameriana expressa na epigrafe deste texto de que "Não se aprende nada que não tenha sido pensado por si mesmo", é coerente com a noção de que "Educação é educar-se" (GADAMER, 2000). Algo que limita as perspectivas prescritivas vigentes na tradição da EF brasileira. Por outro lado, esta abertura, que pode ser lida como espaço de liberdade, não ignora o pertencimento e dívida que temos com o mundo. No entanto, esta relação deve dar-se na "multiplicidade de situações" dado que "o mais livre e independente dos homens, deslocado para circunstâncias uniformes, forma-se de modo mais restritivo" (HUMBOLDT apud HERMANN, 2010, p. 113). O que nos dá o que pensar no quadro atual de massificação e padronização das práticas corporais. As quais se impõem nos espaços educativos se os professores não potencializarem a "multiplicidade de situações", condição de vivenciar a experiência como aqui temos entendido.

Experiência que oportunizada pela alteridade constitutiva de nossa relação dialógica com o outro e com o mundo, redimensionando com isso a própria compreensão de totalidade almejada com a educação. Conforme Hermann, (2010, p. 120)

O conceito de Bildung (formação), transformado pela hermenêutica, implica reconhecer a capacidade de luta do sujeito em se autoeducar, em saber que ele pode reagir para além de todas as adaptações, para além de todos os projetos de sentido que lhe são oferecidos por certos ordenamentos simbólicos e que nunca é totalmente aprendido pelos nossos esquemas conceituais - ou seja, a preservação da dimensão fundamental do conceito clássico de Bildung: a liberdade do individuo para determinar o seu processo de formação. 


\section{ConsideraÇões Finals}

A possibilidade de considerar um referencial hermenêutico para a EF brasileira ainda carece de estudos mais aprofundados em seu interior. Ao que parece, a EF desconhece ou ainda compreende a hermenêutica a partir de uma perspectiva vinculada mais a metodologia ou técnicas da pesquisa do que a um referencial orientador para o trabalho docente e/ou investigativo, salvo raras exceções.

Levar a sério um referencial hermenêutico, inicialmente a partir de um processo de "olhar para dentro" das posturas, dilemas e responsabilidades do trabalho docente na $\mathrm{EF}$, tanto no que se refere a suas relações éticas e políticas, como relações acadêmicocientíficas, poderiam proporcionar desdobramentos em diferentes espaços de intervenção do próprio campo, permitindo inclusive, possibilidades para redimensionar a questão do conhecimento produzido no campo da EF e suas relações com a docência.

Nesse caso, o trabalho da docência se aproxima de um processo de sedução, no qual, inicialmente, o professor precisa ter 'para-si' a importância de seu próprio trabalho, como possibilidade de que esse significado possa ser partilhado com os alunos, passo importante para uma confluência de sentidos.

Da mesma forma, o trabalho docente exige esforço de interpretação de conhecimentos que não foram desenvolvidos a priori para os espaços de intervenção em que o professor atua. Isso significa que a hermenêutica se faz presente em diferentes momentos do trabalho docente, desde o recorte do conteúdo, até as escolhas sobre a forma de trabalhar determinado assunto, etc. O que a EF ainda carece é de um referencial hermenêutico que se torne mais claro ao professor, contribuindo com as tomadas de decisão próprias ao trabalho docente. $\mathrm{O}$ aprofundamento frente a este referencial possibilitaria ampliar a capacidade interpretativa dos docentes, na medida em que sua capacidade de leitura das situações de aula vai 
se alargando. Nessa perspectiva, a experiência da docência nunca se repete, mas sim, acontece em um processo de re-elaboração, reprocessamento, re-interpretação.

Finalizando, a consideração de um referencial hermenêutico possibilitaria redimensionar a questão do trabalho docente, o que pode implicar uma inflexão no entendimento axiológico, teleológico e epistemológico da prática pedagógica dos próprios professores, com devidas implicações para diferentes cenários de intervenção da EF. Essas preocupações possibilitariam abrir o debate frente a questões que emergem do próprio campo ou de suas relações com outros campos do conhecimento. Sinteticamente, conforme expresso na epígrafe inicial, um referencial hermenêutico orientador para o campo da EF pode permitir um caminho para o pensar que poderia ser levado em consideração com seriedade. 


\begin{abstract}
Approximations with the hermeneutic: one referential for the teaching work in the Physical Education field...

Abstract: The main objective of this paper is reflect about the approximations between Physical Education (PE) and hermeneutic, as a possibility for a orientation of teaching work in this field. For that, initially, we present the theoretical-methodological ways. In a second step, we discuss about the presence of articles that addressing or are approximated a one reasoned discussion by hermeneutics, in the field of PE. Finally, we present arguments about the possibilities of a hermeneutic orientation to teaching in the field of Brazilian PE.

Keywords: Physical Education. Philosophy. Faculty.
\end{abstract}

\begin{abstract}
Aproximaciones con la hermenéutica: un referente para el trabajo docente en el campo de la Educación Física...

Resumen: El objetivo principal de este trabajo es reflexionar sobre las aproximaciones entre la Educación Física y la hermenéutica, como una posibilidad de una orientación para o trabajo docente en este campo. Para ello, inicialmente, se presentan las formas teórico-metodológicas. En un segundo paso, se discute sobre la presencia de artículos que tratan acerca de una discusión motivada por la hermenéutica, en el campo de la EF. Finalmente, se presentan argumentos acerca de las posibilidades de una orientación hermenéutica al trabajo docente en el campo de la brasileña EF.
\end{abstract}

Palabras-clave: Educación Física. Filosofia. Docentes.

\title{
REFERÊNCIAS
}

ALVES, Flávio Soarez. Pesquisa Qualitativa: desbravando territórios possíveis de se fazer ciência. Motriz, Rio Claro, v. 15, n. 4, p. 955-963, 2009.

BERTICELLI, Ireno Antônio. A origem normativa da prática educacional na linguagem. ljuí: UNIJUÍ, 2004.

BOLETIM BRASILEIRO DE EDUCAÇÃO FÍSICA. Brasília: 2001- . . Disponível em: www.boletimef.org. Acesso em: 9 - 30 jun. 2010. 
CARDOSO, Carlos Luis. Emergência humana, dimensões da Natureza e corporeidade: sobre as atuais condições espaço-temporais do 'se-movimentar'. Motrivivência, Florianópolis, n. 22, p. 93-114, 2004.

FENSTERSEIFER, Paulo Evaldo. Linguagem, hermenêutica e atividade epistemológica na Educação Física. Movimento, Porto Alegre, v. 15, n. 4, p. 243-256, 2009.

FIAMONCINI, Luciana. Dança na educação: a busca de elementos na arte e na estética. Pensar a Prática, Goiânia, v. 6, p. 59-72, 2003.

GADAMER, Hans-Georg . O caráter oculto da saúde. Petrópolis: Vozes, 2006.

GADAMER, Hans-Georg. Verdade e método I: traços fundamentais de uma hermenêutica filosófica. 8. ed. Petrópolis: Vozes; Bragança Paulista: São Francisco, 2007.

GADAMER, Hans-Georg. La educación es educar-se. Barcelona: Paidós, 2000.

GADAMER, Hans-Georg. Uma conversa com Gadamer. Entrevista realizada por Raquel Abi-Sâmara. UERJ, 2001. Disponível em: http://www.apario.com.br/ forumdeutsch/revistas/vol9/umaconversacomgadamer.pdf. Acesso em 17 fev. 2010.

GADAMER, Hans-Georg. Verdade e método II: complementos e índices. 2. ed.. Petrópolis: Vozes, 2002.

HEIDEGGER, Martin. Ser e tempo. 4. ed. Petrópolis: Vozes, 2009.

HERMANN, Nadja. Autocriação e horizonte comum: ensaios sobre educação ético-estética. ljuí: Unijuí, 2010.

HIRAI, Rodrigo Tetsuo; CARDOSO; Carlos Luís. Para a compreensão da concepção de "aulas abertas" na Educação Física escolar: orientada no aluno, no processo, na problematização, na comunicação e... Motrivivência, Florianópolis, n. 27, p. 119-136, 2006.

HIRAI, Rodrigo Tetsuo; CARDOSO; Carlos Luís. Possibilidades para o ensino orientado na problematização: para a realização da concepção de "Aulas Abertas às Experiências". Movimento, Porto Alegre, v. 15, n. 01, p. 99-116, 2009.

KUHN, Thomas S. A estrutura das revoluções científicas. 9. ed. São Paulo: Perspectiva, 2006.

LAWN, Chris. Compreendendo Gadamer. Petrópolis: Vozes, 2007.

LISPECTOR, Clarice. Água Viva. Rio de Janeiro: Rocco, 1998.

MARQUES. Mario Osório. Conhecimento e modernidade em reconstrução. ljuí: Unijuí, 1993.

MILOVIC, Miroslav. Comunidade da diferença. ljuí: Unijuí, 2004. 
MOTRIVIVÊNCIA. Florianópolis: UFSC, 1988- . Disponível em: http:// www.periodicos.ufsc.br/index.php/motrivivencia. Acesso em: 9 - 30 jun. 2010.

MOTRIZ, revista de educação física. Rio Claro:UNESP, 1995- .Disponível em: http:/ /www.periodicos.rc.biblioteca.unesp.br/index.php/motriz. Acesso em: 9 - 30 jun. 2010.

MOVIMENTO. Porto Alegre, RS : UFRGS, 1994 - Disponível em: http://seer.ufrgs.br/ Movimento. Acesso em: 9 -30 jun. 2010.

PALMER, Richard. Hermenêutica. Lisboa: Edições 70, 2006.

PENSAR A PRÁTICA. Goiânia: UFGO, 1998- . Disponível em: http:// www.revistas.ufg.br/index.php/fef. Acesso em: 9 - 30 jun. 2010.

PORPINO, Karenine de Oliveira. O. Treinamento da ginástica rítmica: reflexões estéticas. Revista Brasileira de Ciências do Esporte, Campinas, v. 26, n. 1, p. 121-133, 2004.

REVISTA BRASILEIRA DE CIÊNCIAS DO ESPORTE. Campinas, SP: CBCE, 1979- . Disponível em: http://www.rbceonline.org.br. Acesso em: 9 - 30 jun. 2010.

REVISTABRASILEIRADE EDUCAÇÃO FÍSICA E ESPORTE. São Paulo : USP/EEFE, 2004- . Disponível em: http://www.revistasusp.sibi.usp.br. Acesso em: 9 -30 jun. 2010.

REVISTA BRASILEIRA DE EDUCAÇÃO FÍSICA, ESPORTE, LAZER E DANÇA. São Paulo: UNIABC, 2006- . Disponível em http://www.refeld.com.br. Acesso em: 9-30 de jun. 2010.

RICOEUR, Paul. Hermenêuticas e ideologias. Petrópolis:Vozes, 2008.

RUEDELL, Aloísio. Hermenêutica. In: GONZÁLEZ, F. J.; FENSTERSEIFER, P. E. Dicionário crítico da Educação Física. ljuí: Unijuí, 2005.

RUEDELL, Aloísio.. Hermenêutica e ensino. In: POMMER, A.; FRAGA, P. D.; SCHNEIDER, P. R. Filosofia e crítica: Festschrift dos 50 anos do Curso de Filosofia da Unijuí. ljuí: Unijuí, 2007.

RUEDELL, Aloísio.. Hermenêutica: da necessidade de interpretar para um modo de pensar. In: SATAMAN, A. S.; FEIL, G. S. (Org.). Linguagem, escrita e mundo. ljuí: Unijuí, 2005a.

SANCHES NETO, Luiz; BETTI, Mauro. Convergência e integração: uma proposta para a educação física de 5a. A $8^{a}$. Série do ensino fundamental. Revista Brasileira de Educação Física e Esporte, São Paulo, v. 22, no. 1, p. 5-23, 2008.

SILVEIRA JUNIOR, Edson Ronei; CARDOSO, Carlos Luiz. Qigong: uma contribuição para a Educação Física escolar. Motrivivência, Florianópolis, n. 23, p. 83-101, 2004. 
TARDIF, Maurice; LESSARD, Claude. O trabalho docente: elementos para uma teoria da docência como profissão de interações humanas. Rio de Janeiro: Vozes, 2005.

TAVARES, Otavio; SOARES, Antonio Jorge; BARTHOLO, Thiago L. "Frozen bananas": esporte, mídia e identidade brasileira nos Jogos Olímpicos de Inverno. Revista Brasileira de Ciências do Esporte, Campinas, v. 29, n. 1, p. 193-208, 2007.

Projeto financiado com Bolsa de Estágio no Exterior (PDEE - Capes)

Endereço para correspondência:

Ricardo Rezer

Endereço: Rua Domingos Cherubin, 91

D. Bairro Palmital. Chapecó (SC)

CEP 89814120

e-mail: rrezer@hotmail.com

Recebido em: 01.04.2011

Aprovado em: 12.05.2011

Movimento, Porto Alegre, v. 17, n. 02, p. 115-135, abr/jun de 2011. 
